\title{
CES
}

COOPERATIVISMO E ECONOMÍA SOCIAL

Núm. 43 (2020-2021), páxs. 97-121

ISSN: $2660-6348$

\section{A ECONOMIA SOCIAL EM PORTUGAL - UM BALANÇO TEÓRICO INSCRITO NA HISTÓRIA}

\author{
THE SOCIAL ECONOMY IN PORTUGAL - A \\ THEORETICAL BALANCE IN HISTORY
}

\author{
Álvaro GARrido*
}

Recepción: 8/10/2021 - Aceptación: 15/10/2021

Universidade de Coimbra, Faculdade de Economia. Investigador do CEIS20. Avenida Dias da Silva, 3004-512 Coimbra, Portugal, alvfrgarrido@gmail.com. 


\section{RESUMO}

Centrado na realidade portuguesa e no percurso histórico das ideias e organizações identificadas com o conceito de Economia Social, o presente artigo propõe um balanço teórico do conceito e discute as vantagens heurísticas da inclusão de uma perspectiva histórica no conhecimento académico do tema. Começa-se por uma discussão da genealogia histórica da ideia de Economia Social no contexto europeu e em Portugal, país em que as organizações e práticas identificadas com o património histórico da Economia Social evidenciam um alto grau de reconhecimento institucional. Após uma síntese crítica das principais fontes que podem proporcionar conhecimento historiográfico sobre as mudanças e continuidades do conceito de Economia Social, salientam-se as evidências do seu processo de institucionalização recente, muito vinculado à transição para a democracia em Portugal. $\mathrm{O}$ artigo fecha com uma proposta de periodização dos marcos históricos da Economia Social portuguesa, uma realidade dinâmica cujo análise histórica e debate historiográfico podem contribuir para a sedimentação das suas práticas e valores comuns

Palavras Chave: Economia Social; Portugal; história; cooperativismo; mutualismo.

\section{ABSTRACT}

Focused on the Portuguese reality and on the historical path of ideas and organizations identified with the concept of Social Economy, this article proposes a theoretical assessment of the concept and discusses the heuristic advantages of including a historical perspective in the academic knowledge of the topic. It begins with a discussion of the historical genealogy of the idea of Social Economy in the European context and in Portugal, a country in which the organizations and practices identified with the historical heritage of Social Economy show a high degree of institutional recognition. After a critical synthesis of the main sources that can provide historiographical knowledge on the changes and continuities of the concept of Social Economy, we highlight the evidence of its recent institutionalisation process, closely linked to the transition to democracy in Portugal. The article closes with a proposal to periodise the historical milestones of the Portuguese Social Economy, a dynamic reality whose historical analysis and historiographical debate can contribute to the consolidation of its practices and common values.

KEYWORLDS: Social Economy; Portugal; history; cooperativism; mutualism. 
SUMÁRIO: 1 INTRODUÇÃO. 2. PERCEPÇÕES INSTITUCIONAIS E ACADÉMICAS DA ECONOMIA SOCIAL EM PORTUGAL. 3. A IMPORTÂNCIA DA HISTÓRIA DA ECONOMIA SOCIAL. 4. DE ONDE VEM A ECONOMIA SOCIAL PORTUGUESA: PROBLEMAS E FONTES. 5. RECONHECIMENTO E INSTITUCIONALIZAÇÃO DA ECONOMIA SOCIAL EM PORTUGAL. 6. CONCLUSÕES. 7. BIBLIOGRAFIA.

SUMMARY: 1. INTRODUCTION. 2. INSTITUTIONAL AND ACADEMIC PERCEPTIONS OF SOCIAL ECONOMY IN PORTUGAL. 3. THE IMPORTANCE OF SOCIAL ECONOMY HISTORY. 4. WHERE DOES THE PORTUGUESE SOCIAL ECONOMY COME FROM: PROBLEMS AND SOURCES. 5. RECOGNITION AND INSTITUTIONALISATION OF THE PORTUGUESE SOCIAL ECONOMY. 6. CONCLUSIONS. 7. BIBLIOGRAPHY.

\section{INTRODUÇÃO}

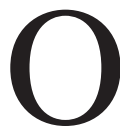
conceito de Economia Social traduz, antes de mais, uma noção jurídica cujas delimitações são normativas. No entanto, se adoptarmos uma perspectiva mais ampla, devemos reconhecer que a noção de Economia Social é, também, uma construção histórica sedimentada ao longo do tempo, que atravessou debates de ideias e disputas de significado. Conceito injuntivo por natureza, combina uma doutrina de Ciência Social e recobre práticas sociais variadas, amiúde informais ${ }^{1}$.

Ao arrepio das definições de pendor normativo e presentista que em regra se lhe atribui, a ideia de Economia Social implica toda uma história de ideias e carrega a sua própria historicidade, composta por vários tempos, contextos e sujeitos. O facto de se tratar de uma ideia social e económica cujo significado se foi preenchendo através de uma negociação constante entre as palavras (doutrina e discurso jurídico) e as coisas (organizações), empresta a este conceito uma densidade histórica particular. Ainda que a expressão "Economia Social" seja compósita ou mesmo redundante, conquanto toda a economia é social, o conceito exprime uma relação dinâmica entre um sujeito (a ideia) e um objecto (as instituições e as práticas sociais).

Historicamente, em particular no contexto europeu da Época Contemporânea, o conceito de Economia Social nunca foi unânime e permaneceu latente durante boa parte do tempo. No entanto, as suas práticas e a sua expressão organizativa

\footnotetext{
1 Esta definição, mais dialéctica do que dicotómica, pertence a D. Demoustier e D. Rousselière, autores de um valioso texto de problematização das filiações históricas da Economia Social: Social economy as a social science and practice: historical perspectives on France, Eleventh World Congress of Social Economics, Social Economics: a Paradigm for a Global Society, Albertville, 8-11 Juin 2004, pp. 41.
} 
foram sempre salientes na vida social e económica das nações e das comunidades locais e, por isso mesmo, nunca deixaram de ser socialmente disputadas.

Esmagada pelo grande confronto entre liberalismo e socialismos que atravessou todo o século XIX e que implodiu com violência no século XX, a ideia de Economia Social não tem uma genealogia histórica linear ${ }^{2}$. Na verdade, o conceito colheu ideias de ambos os lados e habitou, durante largos anos e tal como hoje, um espaço marginal de crítica à Economia Política liberal, cujos principais autores pouco ou nada se preocupavam com a redistribuição e com as formas alternativas de produção de bens e serviços.

A Economia Social é, assim, um conceito dinâmico e em constante renovação, dada a natureza plural dos seus afluentes doutrinais e atenta a variedade organizativa das suas práticas mais e menos instituídas.

No plano doutrinário, a expressão nasceu em França, nos anos trinta do século XIX, num contexto social e económico em que as elites burguesas e aristocráticas temiam que o "corpo social" fosse corrompido pela industrialização e pelas terríveis consequências do pauperismo ${ }^{3}$. Ainda que tenha começado por traduzir uma filosofia moral de raiz organicista, a Economia Social depressa acolheu ideias socialistas e utópicas que remetiam para a construção de comunidades alternativas de vida e de trabalho. Na segunda metade do século XIX, quando o espectro dos socialismos revolucionários se tornou uma fobia colectiva cujo fantasma foi agitado por diversos quadrantes ideológicos e instituições - nomeadamente pelo patronato industrial e pela Igreja Católica -, a ideia de Economia Social alimentou-se, sobretudo, do solidarismo francês, das experiências mutualistas e do movimento sindical reformista.

Apesar de ter encontrado no socialismo cristão e no cooperativismo socialista o seu expoente ético, jurídico e organizacional - talvez o seu modelo mais alternativo ao capitalismo - , a Economia Social vai muito além do campo dos socialismos e evidencia uma plasticidade organizativa considerável, que talvez explique a sua lendária resiliência. Também por isso, importa conhecêla na sua historicidade, isto é, no seu tempo e nos múltiplos contextos de interacção que estabeleceu dentro do sistema capitalista, isto é, em plena coabitação com o Estado e com o mercado 4 .

Ainda que o conhecimento histórico ofereça algumas referências seguras que permitem compreender o caminho das ideias e das organizações, as definições do

\footnotetext{
2 Ver A. Garrido, Cooperação e Solidariedade. Uma História da Economia Social, Lisboa, Tinta da China, 2016, pp. 35-122.

3 A. Gueslin, L'Invention de L'Économie Sociale. Idées, pratiques et imaginaires coopératifs et mutualistes dans la France du XIXe siècle, Paris, Economica, 1998 pp. 27-83.

4 J. L. Laville, A Economia Social e Solidária. Práticas, Teorias e Debates, Coimbra, Almedina/ CES, 2018, pp. 83-100.
} 
conceito de Economia Social estão longe de ser unívocas e provavelmente nunca o serão. Se o debate teórico e académico fecunda o discurso jurídico e alimenta a sua normatividade, o movimento contrário também se verifica. Em regra, os quadros legais vigentes tendem a fixar o conceito na medida em que definem os perfis jurídicos das entidades que, por sua vez, incluem uma imensa pletora de organizações a que correspondem práticas específicas unidas por valores comuns que resultam de uma construção histórica. Sendo a Economia Social composta por realidades organizativas, mas sobretudo por um conjunto de ideias e de práticas em movimento, uma institucionalização demasiado taxativa das suas entidades e organizações pode tornar-se redutora ou mesmo limitativa. Não por acaso, esta crítica costuma ser feita pelos adeptos da expressão alternativa "Economia Solidária", dado que a consideram menos instituinte, mais inclusiva e aberta a uma renovação de práticas, nomeadamente daquelas que emanam de movimentos sociais e das sociabilidades populares.

\section{Percepções institucionais e ACADÉmiCAS Da ECONOMia Social EM Portugal}

Em Portugal, apesar da descoberta relativamente tardia da noção de Economia Social - o conceito foi acolhido no ensino da Economia Política na segunda metade do século XIX, na Faculdade de Direito da Universidade de Coimbra, mas já antes era conhecido e aplicado ${ }^{5}$-, e ainda que as suas organizações associativas tenham conhecido uma implementação difícil no contexto do liberalismo português, a Economia Social foi sempre um conceito à procura de si próprio, sujeito a uma negociação constante entre as ideias e as práticas.

No plano sociológico e jurídico, quer no espaço europeu quer no caso português, actualmente o conceito de Economia Social encontra-se bem definido. $\mathrm{O}$ conceito em si mesmo e as organizações que ele recobre no plano jurídico têm merecido a atenção dos poderes públicos e um reconhecimento institucional inequívoco. Essa particular atenção parece ter crescido num contexto de questionamento, ou mesmo de recuo, do Estado-Providência e quando emergem novas formas de democracia económica associadas à descoberta de localismos e de formas participativas de governo das comunidades ${ }^{6}$.

Apesar das dificuldades de sobrevivência e de afirmação que os investigadores da Economia Social experimentam hoje nas Faculdades de Economia e de Direito - não apenas em Portugal -, o tema da Economia Social e as suas problemáticas

\footnotetext{
5 Ver A. Garrido, ob. cit., pp. 121 e ss.; J. Estivill, "Os primórdios da economia social em Portugal. Contributos de Ramón de la Sagra - I Parte", in Sociologia: Revista da Faculdade de Letras da Universidade do Porto, vol. XXXIII, 2017, pp. 19-45.

6 Ver J. L. Laville, ob. cit., pp. 87 e ss; P. Singer, Ensaios sobre Economia Solidária, Coimbra, Almedina, 2018, pp. 7-21.
} 
têm sido objecto de uma investigação académica multidisciplinar, especialmente focada nas áreas da Sociologia e do Direito, com algumas incursões na Economia, na Gestão e na História. Esse interesse tem justificado a abertura de cursos de pósgraduação dirigidos a profissionais, militantes e simples curiosos. Nos últimos quinze anos tem funcionado em Portugal mais de uma dezena de cursos de pósgraduação e de mestrado dedicados à Economia Social e Solidária, o que pressupõe uma procura significativa, que decorre da incrustação social das entidades e organizações identificadas com este espaço socioeconómico.

Numa contextualização sumária, devemos lembrar que a Economia Social conta em Portugal com um elevado reconhecimento público e até com algumas expressões de discriminação positiva de ordem constitucional, que remontam a 1976; beneficia de um elevado grau de institucionalização e de uma grande proximidade relativamente ao Estado e aos dispositivos públicos de protecção social; conta com uma instância reguladora, a CASES (Cooperativa António Sérgio para a Economia Social), que lhe tem dado visibilidade e uma certa coesão confederativa e que lhe tem assegurado um papel de mediação negocial entre as diversas entidades legalmente reconhecidas e o Estado; conta com uma Lei de Bases aprovada em 2013, por unanimidade, na Assembleia da República, diploma que tipifica as entidades da Economia Social e que lhes define o perfil jurídico; e dispõe ainda de uma Conta Satélite cujas edições de 2013 e 2016 contribuíram muito para conhecer e legitimar o papel social e económico das organizações da Economia Social.

No plano académico, além dos estudos promovidos pela própria CASES a título individual ou em parceria com universidades e investigadores, e além dos estudos promovidos pelo CIRIEC, as principais dinâmicas de investigação, bem como as publicações mais regulares e de maior impacto, têm saído da Universidade de Coimbra (da FEUC e do CES, em particular) e do ISCTE, mas também, a espaços, do ISEG, da Universidade Católica de Lisboa e do Porto, do ISCSP, da Universidade Lusófona e de outras universidades e institutos politécnicos.

Nestas últimas instituições de Ensino Superior, de forma muito variável e reflectindo dinâmicas locais e regionais, tem havido um interesse crescente pela Economia Social, não apenas pelo "sector solidário", mas também pelo "sector mercantil" e em torno das questões do Direito cooperativo ${ }^{7}$. Outro tema central que tem despertado grande interesse da comunidade académica relaciona-se com as questões da cooperação contratualizada entre as IPSS (Instituições Particulares de Solidariedade Social) e o Estado para concretização plurianual de políticas

\footnotetext{
O Direito cooperativo tem em Portugal um lastro conceptual e um sentido de resistência e de especificidade que em boa parte se relaciona com as violações de autonomia de que as cooperativas foram alvo durante o Estado Novo e que se prende, também, com os acesos debates que as diversas versões do Código Cooperativo suscitaram no meio académico e no âmbito do movimento cooperativo.
} 
de solidariedade social e assistência ${ }^{8}$. Mais recentemente, diversos investigadores têm observado de forma crítica os apelos de inovação social dirigidos pelas instituições da União Europeia às organizações da Economia Social e tem havido algum debate académico sobre o tema controverso das empresas sociais e do empreendedorismo social ${ }^{9}$.

\section{A importância da História da Economia Social}

Os actuais debates teóricos sobre o conceito de "Economia Social e Solidária" - dois campos num só terreno - evidenciam a intenção institucional de fixar esse conceito aglutinador, seja na investigação universitária seja ao nível das políticas públicas ${ }^{10}$. Os esforços de elaboração de um corpo teórico definido e inclusivo em torno da ideia de uma "nova Economia Social" - inclusivo, também, em relação ao social business - procuram evitar que o debate teórico fragmente o campo das organizações e coloque em causa todo um caminho de reconhecimento jurídico que, desde os anos oitenta, se construiu em diversos países.

No plano europeu - com a França claramente adiante dos demais países existe uma literatura abundante sobre o tema da Economia Social, as suas ideias, as suas práticas e organizações. Não é nada incomum, porém, que essa produção científica dispute o significado do próprio conceito e defina à sua maneira a moldura jurídica e a expressão organizativa que se pretendem fazer corresponder à ideia de Economia Social.

Em regra, quer em Portugal quer noutros países europeus onde o tema da Economia Social suscita interesse, a análise histórica do fenómeno aparece, muitas vezes, subsumida noutros discursos e limita-se a apontamentos breves que parecem reflectir uma necessidade de legitimação ou uma vinculação excessiva às referências dos doutrinadores. Como notam FRANK MOULAERT e OANA AILENEI, boa parte da literatura científica sobre Economia Social “(...) usa uma perspectiva histórica, mas falha ao retirar consequências analíticas da história"11.

\footnotetext{
8 O principal estudo sobre o tema das IPSS é ainda a tese de Mestrado da socióloga Sílvia Ferreira, o papel das organizações do terceiro sector na reforma das políticas públicas de protecção social. Uma abordagem teórico-histórica, Coimbra, FEUC, 2000. Mais recente, mas indispensável e centrada nas questões da parceria contratual entre o Estado e as IPSS é a tese de mestrado de Cláudia Joaquim, O terceiro sector e a protecção social: Que modelo para Portugal?, Lisboa, ISCTE, 2015.

9 Entre outros projectos de investigação em curso nesta área, destaco o projecto financiado pela FCT e coordenado por Sílvia Ferreira, investigadora do CES da Universidade de Coimbra, intitulado TIMES - Trajetórias Institucionais e Modelos de Empresa Social em Portugal (2017).

10 Uma das publicações mais significativas desse esforço teórico e organizativo recente talvez seja o seguinte livro: D. Hiez et E. Lavillunière (dir.), Vers une théorie de l'Économie Social et Solidaire, Bruxelles, Larcier, 2013.

11 F. Moulaert e O. Ailenei, "Social Economy, Third Sector and Solidarity Relations: A Conceptual Synthesis from History to Present", in Urban Studies, vol. 42, n. 11, October 2005, p. 2038.
} 
Em Portugal, a investigação histórica sobre temas de Economia Social é tímida e recente. Ainda que a história das misericórdias tenha especiais pergaminhos no campo da História Social ${ }^{12}$, e ainda que a história do cooperativismo e do mutualismo tenha merecido alguns estudos importantes e mantido diálogos pontuais com a História Social e Política do país ${ }^{13}$, não existe uma teoria da história da Economia Social. O tema em si mesmo e a definição eminentemente jurídica e trans-histórica do conceito de Economia Social não reúnem o consenso dos historiadores, ainda que essa rejeição também se deva a uma persistente desatenção aos debates das ciências sociais e às dinâmicas de renovação teórica do próprio conceito. Talvez por isso, em Portugal a história da Economia Social não tem um rasto de publicações que se possa considerar expressivo, apesar de algumas tentativas recentes que procuram contrariar essa tendência ${ }^{14}$.

Vale a pena insistir na importância de uma história da Economia Social na medida em que este ângulo de análise pode contribuir vivamente para a sedimentação das suas práticas e do seu património de valores. Importa evitar que a falta de memória histórica desconfigure um espaço organizativo realmente alternativo à economia capitalista mainstream e há que garantir que o campo da Economia Social não se dispõe apenas a replicar tendências instrumentais ou a seguir modismos de ocasião vinculados a possibilidades de financiamento.

\section{De onde Vem a Economia Social portuguesa: problemas e FONTES}

Tal como a define RUI NAMORADO, a Economia Social é "um espaço socioeconómico que corresponde a um conjunto de organizações e de iniciativas

12 Historiadores como Maria Antónia Lopes, Isabel dos Guimarães e Sá, Inês Amorim e José Pedro Paiva, entre outros, têm uma vasta bibliografia sobre o tema, ainda que centrada na Época Moderna e pouco desenvolvida, ainda, para o século XX. Para uma síntese preliminar, vide I. dos Guimarães Sá e M. Antónia Lopes, História Breve das Misericórdias Portuguesas, Coimbra, Imprensa da Universidade de Coimbra, 2008.

13 Relativamente ao cooperativismo, em Portugal devemos destacar as diversas obras do juscooperativista Rui Namorado, bem como as antologias organizadas por Fernando Ferreira da Costa e por João Salazar Leite. As principais obras dos três autores encontram-se indicadas na Bibliografia final deste texto. Relativamente ao mutualismo, a principal obra disponível, hoje uma fonte histórica, é a de Vasco Rosendo, adiante recenseada.

14 Procurando inscrever no campo da historiografia trabalhos de síntese sobre o curso histórico das ideias e das organizações identificadas com o conceito de Economia Social, saliento os dois livros que publiquei: A. Garrido, Cooperação e Solidariedade..., cit.; A. Garrido e D. Pereira, A Economia Social em Movimento. Uma História das Organizações, Lisboa, Tinta da China, 2018. No campo do mutualismo, destaco a obra recente de Joana Dias Pereira, Associativismo Livre. Uma História de Fraternidade e Progresso (1834-1926), Coimbra, Almedina, 2020. 
que a integram quer pelo facto de não fazerem parte do Estado, quer porque nessas entidades e práticas não domina a lógica capitalista do lucro"15.

Esta definição preliminar, construída para traduzir a realidade portuguesa recente, invoca um espaço e um tempo para a Economia Social, categorias nas quais decorre a acção inconfundível das organizações que a Lei de Bases portuguesa tipifica enquanto entidades da Economia Social: cooperativas, associações, fundações, misericórdias, entidades de natureza comunitária e autogestionária ${ }^{16}$.

É certo que a definição legal das entidades e organizações que compõem a Economia Social tem um sentido instituinte, mas essa rigidez oferece a vantagem heurística da classificação tipológica e do agrupamento por categorias institucionais que podemos projectar em tempos recuados.

Observando as dinâmicas da Economia Social no contexto português (de Portugal continental e das ilhas da Madeira e dos Açores, apenas), conclui-se que a Época Contemporânea denuncia dois ciclos históricos fundamentais: i) a longa era em que sobressaiu uma Economia Social intermitente (Monarquia liberal e República, de 1820 a 1910-1926), que primeiro se afirmou e que depois resistiu ou quase desapareceu (durante o regime autoritário e corporativista do Estado Novo, entre 1933 e 1974); ii) a era democrática que vai de 1974 aos nossos dias, marcada por uma Economia Social reconhecida e plural, outra vez em acelerada mudança ${ }^{17}$.

A época contemporânea portuguesa e o período posterior à publicação da chamada lei basilar das sociedades cooperativas, diploma de autoria de Andrade Corvo publicado a 2 de Julho de 1867, constitui o horizonte cronológico deste balanço académico, cujo estado da arte não pretende ser exaustivo.

Os anos da Monarquia liberal portuguesa (1820-1910) e da I República (19101926) exigem uma particular atenção, uma vez que foi nesse contexto político que se afirmou a viva realidade das organizações associativas de trabalhadores, maioritariamente constituídas por associações de socorros mútuos. Por sua vez, o

${ }_{15}$ R. Namorado, O que é a Economia Social?, in A Economia Social em Textos, ${ }^{\circ}{ }^{1}$, CECES-FEUC, 2017, pp. 1-2.

${ }^{16} \mathrm{O}$ artigo $4^{\circ}$ da Lei de Bases da Economia Social (Lei n. ${ }^{\circ}$ 30/2013 de 8 de Maio) diz o seguinte: "Integram a economia social as seguintes entidades, desde que abrangidas pelo ordenamento jurídico português: a) As cooperativas; b) As associações mutualistas; c) As misericórdias; d) As fundações; e) As instituições particulares de solidariedade social não abrangidas pelas alíneas anteriores; f) As associações com fins altruísticos que atuem no âmbito cultural, recreativo, do desporto e do desenvolvimento local; g) As entidades abrangidas pelos subsectores comunitário e autogestionário, integrados nos termos da Constituição no sector cooperativo e social; h) Outras entidades dotadas de personalidade jurídica, que respeitem os princípios orientadores da economia social previstos no artigo $5 .^{\circ} \mathrm{da}$ presente lei e constem da base de dados da economia social".

17 Para uma periodização mais detalhada que acompanha o curso das ideias, das leis e organizações que podemos incluir no conceito de Economia Social em cada época, ver A. Garrido e D. Pereira, A Economia Social em Movimento..., pp. 93-345. 
século XX merece também uma especial atenção, dadas as mudanças qualitativas que conduziram ao reconhecimento tardio da Economia Social em Portugal e as tremendas dificuldades de sobrevivência das mutualidades laborais e das cooperativas culturais, de consumo e de produção durante a ditadura de Salazar e Caetano.

Para o estudo histórico dos períodos mais recuados da Economia Social portuguesa são preciosos os trabalhos de JOSÉ CIPRIANO DA COSTA GOODOLPHIM (1842-1910) ${ }^{18}$, precursor dos estudos de estatística sobre as diversas organizações da Economia Social que o próprio identificou em Portugal e de cuja acção fez boa propaganda no estrangeiro.

COSTA GOODOLPHIM foi o primeiro historiador português da Economia Social. Conhecia bem o conceito e as vivas realidades do mutualismo urbano. Por adesão a esse corpo de princípios e de práticas, subscreveu-o e empenhou-se na sua difusão. Não o fez segundo a versão moralista e conservadora de FRÉDERIC LE PLAY, mas sim numa linha de entusiasmo militante em relação às teses socialistas e republicanas dos "associacionistas" franceses. No momento em que escreveu sobre as associações mutualistas e cooperativas, as sociedades de instrução e beneficência, as caixas económicas e as misericórdias, ainda não viera a público a doutrinação fulgurante de CHARLES GIDE, doutrinador cujas primeiras obras GOODOLPHIM conheceu bem.

Os trabalhos do militante mutualista, inspirados na leitura de obras estrangeiras e, sobretudo, no inquérito às organizações sociais que havia em Portugal, influenciaram os próprios serviços do Estado, que deles se serviu porque o autor se antecipara a percorrer o país e a arrolar todas as mutualidades e associações de socorros mútuos, cooperativas e misericórdias, incluindo o continente e as ilhas. Com minúcia e rigor, GOODOLPHIM inventariou as instituições e distinguiu-as entre si, classificou-as, apurou-lhes as datas de fundação e de aprovação dos

18 José Cipriano da Costa Goodolphim (1842-1910) destacou-se como professor, poeta e publicista. Militante mutualista, desempenhou funções administrativas modestas, durante toda a sua vida, na Companhia Lisbonense de Iluminação a Gás, onde ingressou em 1860. A sua família caíra socialmente com a vitória liberal, em 1834, e foi com várias interrupções que prosseguiu os seus estudos escolares. Aderiu desde cedo aos princípios associativos em torno da previdência e do mutualismo. A sua crença num progresso social de raiz associativa levou-o a ser o representante português em várias reuniões internacionais sobre questões sociais e previdência, ainda no século XIX. O destaque maior na sua produção escrita surge em torno das questões sociais e do arrolamento das organizações da Economia Social: A associação: história de desenvolvimento das associações portuguesas (1876); As caixas económicas em Portugal (1883); As caixas económicas escolares (1883); A Previdência (1889), As Misericórdias (1897), Assistance publique au Portugal (1900), O crédito (1904), Elogio de João José de Sousa Telles: lido na sessão solemne do Albergue dos Inválidos do Trabalho em 3 de Julho de 1904 (1904), Congresso Nacional de Mutualidade: da aç̧ão da mutualidade na federação dos serviços pharmaceuticos: Liga das Associações: das pharmacias (1910), Da acção da mutualidade na economia social: organização das caixas económicas e do serviço de empréstimos sobre penhores apresentada no Congresso Nacional da Mutualidade (1910). 
estatutos. De muitas anotou os serviços sociais que prestavam, das pensões à instrução e à assistência funerária, resumindo-lhes a contabilidade e o balanço anual.

Influenciado pelos grandes debates em torno da Economia Social que se travavam na Europa do seu tempo, GOODOLPHIM não escondeu a intenção de contribuir para uma unificação do sector associativo português, ideia que hoje parece retomar o seu caminho. Fontes secundárias de indispensável consulta, os trabalhos de COSTA GOODOLPHIM antecipam o actual exercício de inventário reflectido na conta satélite da Economia Social. Através de A Associação. História e desenvolvimento das associações portuguesas (1876), A previdencia. Associações de Socorro Mutuo, Cooperativas, Caixas de Pensões e Reformas, Caixas Economicas (1889) e As Misericordias (1897), o autor afirmou-se como o primeiro estudioso do fenómeno associativo, como historiador e estatístico militante.

Em plena alvorada do salazarismo e da institucionalização dos sindicatos corporativos de trabalhadores e patrões, foi publicada outra obra importante que hoje nos serve de fonte para o estudo das instituições conotadas com a Economia Social.

Membro da Direcção da Federação Nacional das Associações de Socorros Mútuos (1915-1930) e deputado ao Congresso da República (1915-1919), DOMINGOS DA CRUZ seguiu uma carreira militar. Foi aí que promoveu e dinamizou a Cooperativa dos Sargentos da Marinha e que se envolveu no movimento cooperativista português. A Mutualidade em Portugal (1933) é um livro que percorre todo o movimento mutualista e cooperativista português, das origens à realidade que havia no começo do Estado Novo. A obra possui alguns dados que complementam a informação estatística oficial, apesar de tudo mais abrangente e detalhada para o período em causa ${ }^{19}$. Mais completos, esses dados existem no Boletim da Previdência Social (1916-1932), publicação oficial do Ministério do Trabalho e Previdência Social. Extinto este Ministério em 1925, o Boletim passou a ser a publicado sob a égide do Ministério das Finanças que, desde então, tutelava o Instituto de Seguros Sociais Obrigatórios e de Previdência Geral.

Depois da longa travessia do deserto que coincidiu com o regime autoritário e corporativista do Estado Novo, importa perceber que Economia Social saiu da Constituição democrática de 1976 e que caminhos ela precisou de percorrer para renascer e merecer o reconhecimento da sociedade portuguesa e dos poderes públicos em especial.

A questão central desse itinerário de transição democrática situa-se na relação dialéctica que as organizações e práticas identificadas com o conceito de Economia Social estabeleceram com o Estado-Providência nascente. Diversos sociólogos e historiadores têm salientado que essa conjugação resultou na institucionalização de direitos sociais de cidadania e numa crescente partilha de responsabilidades

19 Cf. Domingos da Cruz, A mutualidade em Portugal, Coimbra, Imprensa da Universidade, 1933. 
entre o público e o privado nas políticas de segurança social e de solidariedade (previdência e assistência) ${ }^{20}$.

No turbilhão de mudanças que Portugal conheceu nesse período, importa compreender, também, o processo de reemergência de uma Economia Social que depressa se bifurcou, colocando em evidência um sector mercantil (ou contributivo) e um sector não mercantil (também designado solidário). Neste como noutros pilares da Democracia portuguesa e das políticas sociais públicas, tudo indica que os grandes compromissos institucionais foram construídos ao centro do sistema político, sendo certo que a raiz dessas dinâmicas se encontra nos anos revolucionários e nos movimentos sociais que acompanharam o golpe militar de 25 de Abril de 1974. Essas e outras questões relacionadas com o despertar democrático da Economia Social em Portugal e com o seu caminho de reconhecimento público e de progressiva institucionalização são questões centrais de investigação que não dispensam análises de botom-up, nem tão-pouco o estudo das dinâmicas de interacção com os movimentos sociais e com as forças políticas.

Nos anos oitenta do século XX, o renascimento frágil do movimento mutualista e a necessidade de lhe fixar uma memória capaz de evidenciar a sua espessura histórica e a longa tradição social que detém, animaram a União das Mutualidades e o Montepio Geral a promoverem um estudo pormenorizado sobre o mutualismo em Portugal. Depois de ter escrito uma monografia histórica do Montepio, dada à estampa nas comemorações dos cento e cinquenta anos da caixa económica mutualista, celebrados em 1990, Vasco Rosendo lançou-se nesse empreendimento e produziu uma utilíssima obra de síntese, ainda que eminentemente descritiva ${ }^{21}$. Através dessa obra, o mutualismo procurava celebrar a sua própria evidência e disputar um papel de relevo nos sistemas de protecção social da Democracia portuguesa. Após a aprovação da Lei de Bases da Segurança Social portuguesa, em 1984, o principal combate das mutualidades consistia em recuperar terreno na área da previdência social privada, batalha que ainda hoje prosseguem.

Em plena comunicação de propósitos com a obra de Goodolphim, Rosendo empreendeu um amplo levantamento estatístico das organizações mutualistas em Portugal. Esse trabalho minucioso alimentou uma monografia histórica, eminentemente descritiva, mas muito útil, dedicada ao movimento mutualista português. A informação apresentada por Rosendo é quase completa a partir de 1927. Com apoio editorial do Montepio Geral, o autor realizou esse trabalho minucioso usufruindo da sua inserção profissional nos nascentes sistemas de Segurança Social

20 Ver Rui Branco, "Entre Bismarck e Beveridge: sociedade civil e Estado providência em Portugal (1960-2011)", in Análise Social, n. ${ }^{\circ} 224,\left(3 .^{\circ}\right), 2017$, pp. 534-558; Ana Rita Ferreira et alia, "Fundamentos constitucionais da protecção social - continuidades e rupturas", Sociologia, Problemas $e$ Práticas, $\mathrm{n}^{\circ}$ especial, 2016, pp. 71-97.

21 Vasco Rosendo, O Mutualismo em Portugal, Lisboa, Montepio Geral/Multinova, 1996. 
e de Saúde após a Revolução de 25 de Abril de 1974. Foi assim que produziu $O$ mutualismo em Portugal. Dois séculos de história e suas origens (1996) e que retomou muitas das linhas deixadas por Costa Goodolphim mais de cem anos antes. A análise de Rosendo quase se limita às associações de socorros mútuos, mas o seu trabalho oferece uma indispensável radiografia do movimento mutualista em Portugal e do seu percurso histórico.

Por fim, merece realce a obra enciclopédica recentemente editada, os dez volumes de Portugalie Monumenta Misericordiarum (2010), coordenada pelo historiador da Universidade de Coimbra, José Pedro Paiva. A síntese é ampla e inovadora na medida em que conjuga a análise historiográfica com a edição crítica de fontes sobre as misericórdias, sem esquecer o seu inventário nacional e a relação com os poderes laicos e eclesiásticos, nomeadamente a sua interacção muitas vezes oligárquica com os Municípios e elites locais ${ }^{22}$.

A informação contida nas obras e autores que passámos em revista não é homogénea nem deixa de conter algumas omissões e fragilidades no plano estatístico. Não é possível obter dados contínuos e totalmente seguros acerca das quatro grandes famílias da Economia Social portuguesa (associações, mutualidades, cooperativas e misericórdias) para o período compreendido entre 1867 e $1974^{23}$.

Se relativamente ao mutualismo e às misericórdias dispomos de dados nominais alargados e relativamente seguros, para o cooperativismo as dificuldades são maiores. São indispensáveis os números totais dos levantamentos de cooperativas levados a cabo pelos serviços da Previdência Social para o período entre 1890 e 1933 e são muito úteis e fiáveis os números que constam do Boletim Cooperativista publicado por iniciativa de António Sérgio a partir de 1951. De 1974 em diante, multiplicaram-se as cooperativas e produziram-se inúmeros estudos de qualidade variável sobre o movimento cooperativo, nomeadamente por iniciativa do INSCOOP.

Cabe ainda sublinhar a importância dos estudos que a historiadora MIRIAM HALPERN PEREIRA empreendeu sobre as políticas sociais do Estado na sua relação com a vida mutualista e com as práticas de seguro social voluntário. Em "As origens do Estado-Providência em Portugal: As novas fronteiras entre público e privado", a autora produz um autêntico guião para o estudo destas temáticas: propõe uma recensão crítica das obras e fontes impressas disponíveis, inventariando os fundos documentais disponíveis e os dados estatísticos publicados.

\footnotetext{
22 J. Pedro Paiva (coord.), ob. cit.

${ }^{23}$ Advertimos que se trata da realidade portuguesa, dado que no conceito europeu de Economia Social as "famílias" que a compõem incluem as fundações e não as misericórdias, que são uma especificidade portuguesa cuja natureza histórica é de raiz associativa.
} 
Quase duas décadas depois, na esteira das questões levantadas por Pierre Guibentif e António da Silva Leal ${ }^{24}$, o artigo de Halpern Pereira continua a ser muito importante para todos quantos pretendem estudar as políticas sociais sob o ponto de vista da intervenção do Estado ou na perspectiva do movimento mutualista, cooperativo e beneficente que cresceu na sociedade portuguesa após o fim do Antigo Regime, em especial depois de $1834^{25}$. Além do relativo pioneirismo desse artigo, Halpern Pereira opôs argumentos críticos consistentes à visão estigmatizante que a propaganda do Estado Novo difundiu sobre as políticas e instituições de previdência da I República. Curiosamente, essa lenda negra sobre os seguros sociais obrigatórios tem encontrado algum acolhimento em trabalhos recentes cuja tese principal consiste em salientar as continuidades das políticas de previdência democráticas face à previdência corporativa do Estado Novo ${ }^{26}$.

Estas e outras fontes para o estudo do sector social português iluminam uma realidade muito vasta e diversa protagonizada por ideias, instituições e pessoas. No entanto, em Portugal, a história da Economia Social é um tema de reduzida expressão académica, pouco presente em projectos colectivos de investigação e mesmo em estudos individuais ou teses de mestrado e de doutoramento. Recentemente, nota-se um renovado interesse pelo estudo histórico das políticas sociais, que parece associado às expressões de crise do Estado Social. Existem também alguns ensaios importantes sobre a evolução e retardamento do Estado-providência em Portugal.

A análise histórica do associativismo e do mutualismo tem outros pergaminhos e maior expressão editorial. Dispersas e variadas, as obras que incluem alguma análise histórica sobre o mundo associativo e as suas organizações são, na sua maioria, dedicadas ao estudo do sindicalismo operário e das instituições religiosas de assistência social, com destaque para as misericórdias. Na maioria das publicações portuguesas sobre Economia Social, em especial nos estudos e relatórios de natureza institucional, repetem-se em espiral as invocações históricas dos mentores e organizações, em regra a título de legitimação e de culto das origens.

\footnotetext{
24 P. Guibentif, "Génese da Providência Social. Elementos sobre as origens da segurança social portuguesa e suas ligações com o corporativismo, in Ler História, n. ${ }^{\circ}$ 5, 1985, pp. 27-28; A. da Silva Leal, Temas de Segurança Social, Lisboa, União das Mutualidades Portuguesas, 1998.

${ }^{25}$ Cf. M. Halpern Pereira, "As origens do Estado-Providência em Portugal: As novas fronteiras entre público e privado", in Ler História, n 37, 1999, pp. 45-61; J. L. Cardoso e M. Manuela Rocha, "Corporativismo e Estado Providència (1933-1962)", in Ler História, no 45, 2003, pp. 111-135.

${ }^{26}$ Entre outros trabalhos, vide a dissertação de mestrado de Daniel Carolo, A reforma da previdência social de 1962 na institucionalização do Estado-Providência em Portugal, dissertação de Mestrado em Economia e Política Social, ISEG, 2006.
} 


\section{RECONHECIMENTO E INSTITUCIONALIZAÇÃo DA ECONOMIA SOCIAL EM PORTUGal}

O reconhecimento de um "sector cooperativo e social" na primeira Constituição portuguesa do regime democrático, em 1976, foi o fecho dinâmico de um longo percurso histórico. Um caminho marcado pela limitada expressão do movimento cooperativo e das associações em geral, mas também o ponto de partida para formulações mais abrangentes de uma Economia Social que tardou a ser reconhecida nas suas múltiplas dimensões e práticas de movimento e doutrina.

Neste processo de afirmação institucional que implicou todo um reconhecimento político e uma tradução jurídica adequada, a Economia Social não foi apenas aquilo que quis ser, uma vez que a construção histórica de um EstadoProvidência democrático influiu muito na sua fisionomia organizativa e porque as desigualdades sociais e as assimetrias de desenvolvimento do território exigiram soluções auto-organizadas de produção de bens e serviços.

Se na década de oitenta a noção de Economia Social colhera poucas adesões em Portugal, nos anos noventa e na viragem do milénio essa socialização conheceu alguns progressos institucionais, sobretudo graças aos efeitos do Pacto de Cooperação e Solidariedade, ao trabalho do INSCOOP e aos esforços de convergência das principais entidades, partindo em regra do sector cooperativo. Volvida a idade reivindicativa do cooperativismo, seguiu-se um ciclo de maior diálogo entre o movimento cooperativo, as universidades e o Estado. Essa fase culminou no I Congresso das Cooperativas Portuguesas, realizado em Abril de $1999^{27}$ o primeiro desde finais do século XIX -, cuja presidência pertenceu ao próprio Presidente do INSCOOP ${ }^{28}$. O modelo repetir-se-ia em 2004, aquando do segundo Congresso.

Concluída a estruturação legal e organizativa dos diversos ramos cooperativos, havia que cuidar da afirmação empresarial das cooperativas e que manter a liderança do sector no âmbito mais vasto da Economia Social, uma ideia cada vez menos difusa. O I Congresso das Cooperativas Portuguesas foi particularmente importante para a sedimentação da Economia Social na medida em que foi precedido por uma série de trabalhos e debates preparatórios, de norte a sul

\footnotetext{
27 Veja-se as respectivas actas e a listagem das cooperativas que participaram: Congresso das Cooperativas Portuguesas (16 e 17 de Abril de 1999), Lisboa, Instituto António Sérgio do Sector Cooperativo, 1999.

28 Ver J. Salazar Leite, "Relações entre cooperativas e Estado em Portugal”, cit., p. 15. Entre os estudos de inventário e delimitação conceitual e organizativa da Economia Social produzidos pelo INSCOOP devemos destacar, pela sua consistência, o livro de F. Nunes, L. Reto e M. Carneiro, O Terceiro Sector em Portugal: Delimitação, Caracterização e Potencialidades, Lisboa, INSCOOP, 2001 (prefácio do ministro do Trabalho e da Solidariedade Paulo Pedroso).
} 
do país, promovidos pela Rede Portuguesa para a Formação do Terceiro Sector ${ }^{29}$. Apelava-se a uma maior integração do cooperativismo em estruturas associativas. O trabalho da Rede decorreu ao longo de vários anos e estabeleceu sinergias relevantes entre as instituições que dela faziam parte, instituições de Ensino Superior e entidades da Economia Social. A actual decisão de constituir a Confederação da Economia Social teve na Rede um precedente importante.

Só na revisão de 1997 a Economia Social ficou claramente reconhecida na Constituição portuguesa. A polissemia organizativa da Economia Social e os diversos campos que nela então coabitavam, cada entidade com o seu património de valores, parece ter obrigado os legisladores a acolher, além dos subsectores comunitário e autogestionário anteriormente incluídos no sector público, um "subsector solidário". Na prática, tratou-se de incluir o mutualismo e as entidades com estatuto de IPSS na galáxia institucional das diversas entidades da Economia Social. Era esse o interesse dos dirigentes mutualistas e das forças políticas que mais se lhe ligavam e só desse modo se poderia avançar.

Beneficiando de dinâmicas políticas e da mobilização das instituições, na viragem do século a Economia Social começava a ser um horizonte mais nítido e consolidado. As principais forças políticas já lhe atribuíam importância e esse envolvimento repercutiu-se nas opções das entidades que a viriam a integrar.

No plano académico, o conceito de Economia Social ganhou corpo e despertou um renovado interesse na investigação e no ensino pós-graduado. Na Universidade de Coimbra, o Centro de Estudos Cooperativos que havia sido criado pelo juscooperativista RUI NAMORADO em 1982, estendeu os seus objectivos à investigação e formação na área da Economia Social, Economia Solidária e Terceiro Sector (organizações, agentes e doutrinadores). A realização de congressos nacionais e ibéricos de Economia Social e a diversificação de um pensamento cooperativo mais adaptado às realidades da globalização e ao processo de institucionalização da Economia Social foram dinâmicas importantes ${ }^{30}$.

\footnotetext{
29 Uma parte importante do trabalho de reflexão teórica e prática dinamizado pela Rede Portuguesa para a Formação do Terceiro Sector e de preparação do Congresso das Cooperativas de 1999 encontra-se reunido no seguinte volume: Manuel Belo Moreira (coord.), O Cooperativismo no Novo Milénio. A Vantagem Cooperativa, Lisboa, INSCOOP, 1999. Os textos de Manuel Belo Moreira e de Fernando Ferreira da Costa são, talvez, os mais elucidativos da transição de um cooperativismo maduro para uma Economia Social reconhecida e articulada com as funções sociais do Estado.

30 É de destacar a publicação da revista Pensamento Cooperativo, revista de estudos cooperativos, editada pelo INSCOOP a partir de Dezembro de 2000 e dirigida por Manuel Canaveira de Campos. E já antes, o Boletim do Centro de Estudos Cooperativos da Faculdade de Economia da Universidade de Coimbra, dirigido por Rui Namorado, cujo primeiro número saíra em Março de 1987. O jurista e sociólogo Rui Namorado é, seguramente, o autor português que produziu, até hoje, obra mais extensa e relevante sobre temas cooperativos e de Economia Social. É ímpar o seu contributo para o ordenamento jurídico do sector cooperativo da Democracia portuguesa.
} 
O conceito de Economia Social abria-se a novas práticas e formas de acção colectiva, também reunidas no conceito de Economia Solidária, cujo principal entusiasta sempre foi, em Portugal, o economista ROGÉRIO ROQUE AMARO ${ }^{31}$, juntamente com o sociólogo PEDRO HESPANHA, especialmente interessado no fenómeno das economias populares e noutras formas reciprocitárias de Economia Social $^{32}$.

A complementaridade da Economia Social com a Economia Solidária correspondia ao modelo organizativo que a Economia Social exibia nos países onde o conceito já fizera mais caminho e conquistara algum reconhecimento. Em Portugal, também nesse aspecto o papel do INSCOOP foi importante. A ideia de uma confederação da Economia Social já se murmurava nesses tempos, mas havia a consciência de que só se poderia avançar nesse sentido se as pessoas e as organizações se unissem. Para isso havia que convencer outras entidades da Economia Social, além das cooperativas, a fazerem parte da CASES. Primeiro entraram as cooperativas e as mutualidades. Representando as entidades com estatuto de IPSS, a CNIS entraria mais tarde. Por vontade própria, o Centro Português de Fundações declinou o convite ${ }^{33}$.

O Decreto-Lei n. ${ }^{\circ}$ 282/2009, publicado em Diário da República a 7 de Outubro de 2009 (Governo de José Sócrates, tendo como ministro do Trabalho e Solidariedade José António Vieira da Silva) extingue o INSCOOP - Instituto António Sérgio do Sector Cooperativo, I. P., e cria a CASES - Cooperativa António Sérgio para a Economia Social - Cooperativa de Interesse Público de Responsabilidade Limitada. Através do Despacho 26623/2009, de 26 de Novembro, o Governo autoriza o Instituto de Emprego e Formação Profissional (IEFP) a subscrever, em nome do Estado, o capital social da CASES.

O preâmbulo do diploma criador da CASES invoca o reconhecimento constitucional do "sector cooperativo e social", exprime sem tibiezas uma intenção de reforço do papel da Economia Social nas políticas públicas e destaca assim as vantagens da sua diversidade interna: "Independentemente da diversidade de estatutos jurídicos que podem adoptar, as organizações da Economia Social partilham princípios e valores comuns, designadamente o espírito de iniciativa e de entre-

${ }^{31}$ Nas obras publicadas por R. Roque Amaro destacam-se os seus artigos e notas editoriais incluídos nos dez números da Revista de Economia Solidária e diversos estudos sobre desenvolvimento local e "empoderamento" de comunidades.

${ }^{32}$ Na vasta obra de Pedro Hespanha, entre os trabalhos mais significativos da sua visão da Economia Social importa destacar os seguintes: o número 84 (2009) da Revista Crítica de Ciências Sociais, que organizou com Rui Namorado, dedicado ao tema "Os desafios da economia solidária"; Pedro Hespanha e Aline Mendonça dos Santos (orgs.), Economia Solidária: questões teóricas e epistemológicas, Coimbra, Almedina/CES, 2011; A. D. Cattani; J.-L. Laville; L. I. Gaiger; P. Hespanha (coord.), Dicionário Internacional da Outra Economia, cit.

33 A. Garrido e D. Pereira, A Economia Social em Movimento..., cit., pp. 335-337. 
ajuda, determinantes para o fortalecimento da democracia participativa e para a construção de uma sociedade mais solidária, para além de apresentarem um forte denominador comum ao combinarem a actividade económica sem fins lucrativos, com a prossecução de fins de declarado interesse público"34.

No plano das ideias e das formas de articulação entre sistemas de provisão de bens e serviços sociais, a formulação é ainda mais eloquente: ainda que relacionada com a reorganização (emagrecimento) do Ministério do Trabalho e da Solidariedade Social, a criação da CASES era coerente com a recente Resolução do Parlamento Europeu sobre a Economia Social. Aí se reafirmara que a "aliança entre o Estado e as organizações da economia social é crucial face à sua capacidade de desenvolver, no interior das economias de mercado, redes de solidariedade, dinâmicas e espaços de resolução de problemas, numa base de proximidade, revitalizando novos modelos de interacção entre o Estado a sociedade civil organizada e o mercado" 35 . O artigo $4^{\circ}$ do Decreto-Lei define bem as atribuições da CASES: entre outras, "dinamizar a actividade económica e social do sector da economia social" e "fomentar o reconhecimento e capacitação institucional das organizações da economia social"36.

O papel da CASES confirmou-se fundamental para a dinâmica convergente das diversas entidades da Economia Social. Reforçou o conhecimento e socialização dos seus princípios e realidades e ofereceu estabilidade às relações com o Estado. Assentando numa parceria entre o Estado e as entidades representativas da Economia Social, a CASES tem contribuído muito para o fortalecimento, dinamização e qualificação das entidades e das práticas de Economia Social. Foi decisivo o seu papel na criação de condições para a aprovação de uma lei basilar da Economia Social, necessariamente plural mas vertebrada sobre os princípios cooperativos que se inscrevem numa longa tradição histórica e consagrados pela Aliança Cooperativa Internacional. A seguir à Espanha, que o fizera em 2011, Portugal foi o segundo país europeu a publicar uma lei de bases para a Economia Social.

A Lei de Bases da Economia Social (LBES) foi aprovada por unanimidade pela Assembleia da República em 15 de Março de 2013, após uma longa discussão na especialidade do projecto de lei que a precedeu. A LBES tem-se revelado um marco jurídico fundamental para o amadurecimento da Economia Social, na medida em que foi completada por diversos decretos de desenvolvimento e porque, como notou DEOLINDA MEIRA, a lei exprime de forma inequívoca um "reconhecimento institucional e jurídico explícito do sector da Economia Social" ${ }^{37}$.

34 Diário da República, I Ia série, n. ${ }^{\circ}$ 194/2009, 7 de Outubro de 2009, Decreto-Lei n. ${ }^{\circ}$ 282/2009 (do preâmbulo).

35 Idem.

36 Alíneas c) e d), respectivamente, do ponto 2 do artigo $4^{\circ}$.

37 Deolinda A. Meira, "Lei de Bases da Economia Social: do projecto ao texto final", art. cit., p. 4. 
A Lei de Bases deu uma sequência coerente e sistémica a um longo percurso de reconhecimento e de institucionalização da Economia Social, que aqui acompanhámos. A delimitação do âmbito das entidades e dos princípios comuns que as unem; a definição de políticas de fomento e de qualificação das práticas de Economia Social; e a identificação das formas de relacionamento das entidades com os poderes públicos constituem o escopo da $\mathrm{LBES}^{38}$.

A definição de Economia Social consagrada na Lei de Bases, de natureza subjectiva e jurídica, dá forma aos critérios que qualificam e delimitam as entidades que a compõem, de acordo com a actividade desenvolvida e o fim prosseguido. Como nota DEOLINDA MEIRA, "de facto o legislador associa a noção de Economia Social a um específico objectivo social, traduzido numa actividade económico-social, a qual terá por finalidade a prossecução de um interesse geral" ${ }^{39}$. Na explicitação desses critérios de pertença à Economia Social, a Lei de Bases representa as entidades como parceiros do Estado Social ou, na expressão do Conselho Nacional para a Economia Social, traduz uma "parceria público-social".

Por detrás das classificações jurídicas e conceituais inscritas na Lei de Bases encontra-se a realidade funcional das entidades e organizações da Economia Social e supõe-se todo um processo histórico que, em boa medida, permite compreender o sentido comum das ideias e das práticas desse imenso sector social.

\section{CONClusÕes}

Em Portugal, a expressão histórica da Economia Social não é apenas um reflexo dos debates europeus e das tremendas tensões que se estabeleceram entre correntes de ideias e soluções de protecção social nos séculos XIX e XX. Apesar da escassa autonomia das propostas de associação e cooperação deixadas pelos autores que se costumam incluir na galeria histórica da Economia Social portuguesa, e pese a filiação das suas ideias nos escritos de eminentes doutrinadores europeus, o caso português tem a sua especificidade.

Em primeiro lugar, porque o desenvolvimento das associações populares portuguesas não foi tão modesto como seria de supor numa sociedade que conheceu tarde a industrialização e que, por isso, não criou uma classe trabalhadora tão numerosa quanto se viu noutros países.

Em segundo lugar, atente-se no contraste entre os esforços de codificação de leis associativas modernas e a modéstia da produção doutrinal oferecida aos militantes associativos e da cooperação, voluntarismo que reflecte o que se passou nas políticas sociais em geral.

38 Ver Rui Namorado, A Economia Social em Acção, cit., pp. 7-9; Deolinda Meira, "Lei de Bases da Economia Social: do projecto ao texto final", in Revista Jurídica, n 24, 2013, p. 4.

39 Id., ibidem, p. 9. 
Em terceiro lugar, embora antes de 1910 a intervenção social do Estado e as políticas de protecção social tivessem uma dimensão modesta, a prática dos seguros sociais permanecia profundamente vinculada às associações mutualistas, cujo crescimento foi notório até finais da década de vinte. Esta evidência explica por que razão as tensões entre o mutualismo e as primeiras formas de estadoprovidência, erigidas pela República em 1919, foram quase constantes, mesmo depois da institucionalização dos seguros sociais obrigatórios.

Por último, se essa coabitação difícil entre mutualismo e previdência também se identifica noutros países que no começo do século XX conheceram a novidade do seguro social obrigatório, só a Espanha se compara a Portugal relativamente à persistência histórica de uma assistência social pública, ou imposta pelo Estado com apoio da Igreja Católica. Contra a corrente do que sucedeu na maioria dos países, na Península Ibérica os "estados novos" salazarista e franquista instituíram sistemas corporativistas de assistência social que visavam desmantelar quer o seguro social obrigatório, que acusaram de "socializante", quer o mutualismo livre, conotado com a anarquia e a revolução. No lugar de ambos, a política social do Estado Novo português colocou um modelo assistencialista de protecção social subordinado à sua lógica arbitrária, paternalista e antidemocrática - a previdência corporativa.

A seguir à Revolução de 25 de Abril de 1974 e sobretudo depois de a Constituição democrática de 1976 ter declarado a existência de um "sector cooperativo" da economia (artigo 82. ${ }^{\circ}$ ), multiplicaram-se os estudos e as edições sobre as origens do cooperativismo e acerca dos seus precedentes associativos e mutualistas. Muitas dessas obras centram-se na abordagem histórica do movimento operário e da sua cultura de classe, digressão que inclui referências de culto ao movimento mutualista, em busca das suas raízes populares e "obreiristas"40.

Além dessa fulgurante afirmação de uma história socialista e marxista das classes operárias que valorizava muito as ligações dos movimentos operário e associativo, surgiram boas antologias de textos dos doutrinadores associativos e cooperativistas portugueses ${ }^{41}$. Nesse movimento de expressão e redescoberta de uma tradição cooperativa resistente e de fundas raízes que se queria identifica-

\footnotetext{
40 Devemos nomear, antes de mais, as publicações pioneiras de César Oliveira, por anteriores ao 25 de Abril de 1974: A Comuna de Paris e os Socialistas Portugueses, Porto, Brasília Editora, 1971; O Operariado e a República Democrática (1910-1914), Porto, Afrontamento, 1972. Destacam-se ainda, o livro de Manuel Villaverde Cabral, O Operariado nas Vésperas da República (1909-1910), Lisboa, Presença - GIS, 1977 e a obra de síntese de Carlos da Fonseca, História do Movimento Operário e das Ideias Socialistas em Portugal, 4 vols., Lisboa, Publicações Europa-América, 1979.
}

41 A principal antologia publicada nesse contexto, desde então uma fonte de extraordinária riqueza para o estudo da Economia Social em Portugal, pertence a Fernando Ferreira da Costa, Doutrinadores Cooperativistas Portugueses. Subsídios para o Estudo do Sector Cooperativo Português, Lisboa, Livros Horizonte, 1978 (prefácio de Henrique de Barros). Dois anos antes, Ferreira da Costa, professor da Faculdade de Economia da Universidade do Porto e Presidente do Instituto António Sérgio do Sector 
da com um socialismo cooperativista, libertou-se a memória de António Sérgio e exaltaram-se os escritos de outros mentores portugueses da Economia Social. Os principais trabalhos que dão conta desse esforço genealógico distinguem com incisão os autores "pré-cooperativos" dos "cooperativos" propriamente ditos ${ }^{42}$.

Quer isto dizer que nessa historiografia consistente, mas datada, sobre as organizações e práticas de Economia Social, o património cooperativo ocupa um lugar cimeiro. Ao movimento associativo e mutualista, bem como a outras expressões de Economia Social, ensaístas militantes como ANTÓNIO SÉRGIO, HENRIQUE DE BARROS, FERNANDO FERREIRA DA COSTA ou, mais recentemente, RUI NAMORADO, reconhecem um papel complementar e de sedimentação histórica relativamente ao cooperativismo socialista.

Confirma-se que não estamos em terreno neutro, antes num vasto universo de galáxias e constelações. Estas metáforas comuns na linguagem da Economia Social, traduzem bem a diversidade dos seus agrupamentos doutrinais e o diálogo patrimonial que os cooperativistas portugueses mantêm com ANTÓNIO SÉRGIO, sem dúvida o mais prolífero e reconhecido mentor de uma Economia Social progressista ou empenhada num reformismo social de sentido democrático.

Apesar da relativa abundância de fontes históricas para que a construção de uma história da Economia Social surgisse, esse imenso filão permanece pouco explorado. Nos anos noventa, a afirmação de uma nova história social, mais interessada nos pobres e indigentes e nas sociabilidades de baixo estatuto do que nas estruturas sociais e classes superiores, animou alguns estudos de fronteira, em especial dedicados às concepções e práticas históricas de assistência na pobreza e na doença ${ }^{43}$. Mais recentemente, acompanhando os discursos de crise do estado-providência e procurando pensar historicamente a relação entre o público e o privado nos sistemas de protecção social, alguns historiadores têm reconciliado a análise das origens do estado-providência ${ }^{44}$ com a compreensão das dinâmicas do mutualismo voluntário. Esta perspectiva foi inaugurada por juristas e sociólogos, como

Cooperativo (INSCOOP), publicara As Cooperativas na Legislação Portuguesa, Lisboa, Livraria Petrony, 1976.

${ }^{42}$ Cf. id., ibidem, pp. 7-9. Tal distinção consta, desde logo, do prefácio de Henrique de Barros, e encontra-se novamente no estudo introdutório incluído pelo autor da selecta de textos, Fernando Ferreira da Costa.

${ }^{43}$ Uma boa amostra dessas várias frentes da História Social encontra-se na síntese redigida por Maria Antónia Lopes para o quinto volume da História de Portugal dirigida por José Mattoso, cujo texto abrange todo o período liberal (1820-1910). Cf. M. Antonia Lopes, Os pobres e a assistência pública, in J. Mattoso (dir.), História de Portugal, Círculo de Leitores, Lisboa, 1993, vol. V, pp. 501-515.

${ }^{44}$ Cf. G. Esping-Andersen, The Three Worlds of Welfare Capitalism, Cambridge, Polity Press, 1990, pp. 1-34. 
ANTÓNIO DA SILVA LEAL ${ }^{45}$ e PIERRE GUIBENTIF ${ }^{46}$, e depois aprofundada pela historiadora MIRIAM HALPERN PEREIRA, entre outros autores ${ }^{47}$. Esta via de interpretação oferece a vantagem de captar as tensões e convergências históricas entre a natureza e actuação das múltiplas organizações do movimento mutualista, por um lado, e a institucionalização estatal dos seguros sociais, por outro.

Numa sociedade que conheceu tarde o Estado-Providência e que continua a debater-se com desigualdades sociais persistentes e níveis de pobreza difíceis de combater, as relações entre o público e o privado na construção de formas de previdência e de assistência são um tópico central da agenda de investigação sobre temas de Economia Social. Entendida num sentido amplo - não apenas na acepção redutora que o assistencialismo católico lhe atribui -, cremos que o conceito de solidariedade e as suas práticas precisam de ser incluídos explicitamente no discurso legislativo, nas instituições e no meio académico. Neste como noutros momentos históricos, a gramática da Economia Social é dinâmica e plural e tem a sua historicidade.

\section{Bibliografia}

R. BRANCO, «Entre Bismarck e Beveridge: sociedade civil e Estado providência em Portugal (1960-2011)», ANÁLISE SOCIAL, n. ${ }^{\circ} 224,\left(3 .^{\circ}\right),(2017)$, pp. 534-558.

A. BRIGGS, «The Welfare State in Historical Perspective», in EUROPEAN JOURNAL OF SOCIOLOGY, vol. 11, (1961), pp.221-258.

M. VILLAVERDE CABRAL, O Operariado nas Vésperas da República (1909-1910), Lisboa, Presença- GIS, 1977.

JL. CARDOSO e MM. ROCHA, «Corporativismo e Estado Providència (1933-1962)», Ler História, $\mathrm{n}^{\circ}$ 45, 2003, pp. 111-135.

D. CAROLO, A reforma da previdência social de 1962 na institucionalização do EstadoProvidência em Portugal, dissertação de Mestrado em Economia e Política Social, ISEG, 2006.

R. CASTEL, Les metamorfoses de la question sociale. Une chronique du salariat, Paris, Gallimard, 2012.

AD. CATTANI, JL. LAVILLE, L. GAIGER; P. HESPANHA (orgs.), Dicionário Internacional da Outra Economia, Coimbra, Almedina/CES, 2009.

F F. DA COSTA, António Sérgio. Sobre o Sistema Cooperativista, Lisboa, Livraria Sá da Costa Editora, 1984.

- As Cooperativas e a Economia Social, Lisboa, Livros Horizonte, 1986.

- As Cooperativas na Legislação Portuguesa, Lisboa, Livraria Petrony, 1976.

\footnotetext{
45 A. da Silva Leal, ob. cit.

46 P. Guibentif, art. cit.

47 M. Halpern Pereira, art. cit.
} 
- Doutrinadores Cooperativistas Portugueses. Subsídios para o estudo do sector cooperativo português, Lisboa, Livros Horizonte, 1978.

D. CRUZ, «A mutualidade em Portugal», Coimbra, Imprensa da Universidade, 1933.

J. DEFOURNY, M. NYSSENS (dir.), Économie sociale et solidaire. Socioéconomie du $3 e$ secteur, Bruxelles, De Boeck, 2017.

D. DEMOUSTIER, D. ROUSSELIÈRE, Social economy as a social science and practice: historical perspectives on France, Eleventh World Congress of Social Economics, Social Economics: a Paradigm for a Global Society, Albertville, 8-11 Juin 2004 [documento online].

H. DESROCHE, Histoires d'économies sociales. D’un Tiers État au tiers secteur, 1971-1991, Paris, Syros/CJDES, 1991.

J. DONZELOT, L'invention du social. Essai sur le déclin des passions politiques, Paris, Éditions du Seuil, 1994.

JF. DRAPERI, Jean-François, Comprendre l'économie sociale, Paris, Dunod, 2007.

G. ESPING-ANDERSEN, The Three Worlds of Welfare Capitalism, Princeton, Princeton University Press, 1990.

J. ESTIVILL, «Os primórdios da economia social em Portugal. Contributos de Ramón de la Sagra - I Parte», Sociologia: Revista da Faculdade de Letras da Universidade do Porto, Vol. XXXIII, 2017, pp. 19-45.

AR. FERREIRA, D. CAROLO, M. TRIGO PEREIRA, PA. e SILVA, «Fundamentos constitucionais da protecção social - continuidades e rupturas», Sociologia, Problemas e Práticas, n. ${ }^{\circ}$ especial, 2016, pp. 71-97.

S. FERREIRA, O papel das organizações do terceiro sector na reforma das políticas públicas de protecção social. Uma abordagem teórico-histórica, Coimbra, Tese de Mestrado em Sociologia apresentada à FEUC, 2000.

C. FONSECA, História do Movimento Operário e das Ideias Socialistas em Portugal, 4 vols., Lisboa, Publicações Europa-América, 1979.

P. FRÉMEAUX, La Nouvelle Alternative? Enquête sur l'économie sociale et solidaire, Paris, Alternatives Économiques/Les Petits Matins, 2011.

A. GARRIDO, Cooperação e Solidariedade - Uma História da Economia Social, Lisboa, Tinta da China, 2016.

A. GARRIDO, D. PEREIRA A Economia Social em Movimento. Uma História das Organizações, Lisboa, Tinta da China, 2018.

A. GUESLIN, L'Invention de L'Économie Sociale. Idées, pratiques et imaginaires coopératifs et mutualistes dans la France du XIXe siècle, Paris, Economica, 1998.

P. GUIBENTIF, «Génese da Providência Social. Elementos sobre as origens da segurança social portuguesa e suas ligações com o corporativismo», Ler História, n. ${ }^{\circ}$ 5, 1985, pp. 27-28.

M. HÉLY, P. MOULÉVRIER, L'économie sociale et solidaire: de l'utopie aux pratiques, Paris, La Dispute, 2013.

P. HESPANHA, R. NAMORADO (orgs.), «Os Desafios da Economia Solidária», Revista Crítica de Ciências Sociais, n. ${ }^{\circ} 84$ (n. ${ }^{\circ}$ especial), 2009.

P. HESPANHA, AM. SANTOS (org.), Economia Solidária: questões teóricas e epistemológicas, Coimbra, Almedina/CES, 2011. 
D. HIEZ, E. LAVILLUNIÈRE (dir.), Vers une théorie de l'Économie Sociale et Solidaire, Bruxelles, Larcier, 2013.

J. HORNE, Le Musée Social. Aux origines de l'État Providence, Paris, Belin, 2004.

C. JOAQUIM, O terceiro sector e a protecção social: Que modelo para Portugal?, Lisboa, Dissertação de Mestrado em Políticas Públicas apresentada ao ISCTE - Instituto Universitário de Lisboa, 2015.

JL. LAVILlE, A Economia Social e Solidária. Práticas, Teorias e Debates, Coimbra, Almedina/CES, 2018.

JL. LAVILLE, L'économie solidaire. Une perspective internationale, Paris, Hachette, 2007.

DA SILVA LEAL, Temas de Segurança Social, Lisboa, União das Mutualidades Portuguesas, 1998.

J. SALAZAR LEITE, Boletim Cooperativista. António Sérgio e discípulos, Lisboa, CASES, 2012.

-Cooperação e Intercooperação, Lisboa, Livros Horizonte, 1982.

- Enquadramento Histórico-Social do Movimento Cooperativo, Lisboa, INSCOOP, 1994.

D. APARÍCIO MEIRA, «A Lei de Bases da Economia Social Portuguesa; do projecto ao texto final», Revista Jurídica, n. ${ }^{\circ}$ 24, 2013, pp. 1-32.

JL. MONZÓN CAMPOS, R. CHAVES ÁVILA, Evolución reciente de la Économia Social en la Unión Europea, Bruselas, Unión Europea, Comité Económico y Social Europeo, 2017.

F. MOULAERT, O. AILENEI, «Social Economy, Third Sector and Solidarity Relations: A Conceptual Synthesis from History to Present», Urban Studies, vol. 42, n. ${ }^{\circ}$ 11, October 2005, pp. 2037-2053.

M. BELO MOREIRA (coord.), O Cooperativismo no Novo Milénio. A Vantagem Cooperativa, Lisboa, INSCOOP, 1999.

R. NAMORADO (coord.), Economia Social em Acção, Coimbra, Almedina, 2014.

- Introdução ao Direito Cooperativo. Para uma expressão jurídica da cooperatividade, Coimbra, Almedina, 2000.

- O essencial sobre Cooperativas, Lisboa, Imprensa Nacional-Casa da Moeda, 2013.

- O Mistério do Cooperativismo. Da Cooperação ao Movimento Cooperativo, Coimbra, Almedina, 2013.

- «Para uma economia solidária - a partir do caso português», Revista Crítica de Ciências Sociais, n. ${ }^{\circ} 84,2009$, pp. 65-80.

- «O que é a Economia Social?», A Economia Social em Textos, n. ${ }^{\circ}$ 1, CECES-FEUC, 2017.

F. NUNES, L. RETO, M. CARNEIRO, O Terceiro Sector em Portugal: Delimitação, Caracterização e Potencialidades, Lisboa, INSCOOP, 2001.

C. OLIVEIRA, A Comuna de Paris e os Socialistas Portugueses, Porto, Brasília Editora, 1971.

- O Operariado e a República Democrática (1910-1914), Porto, Afrontamento, 1972.

J. PAIVA (coord.), Portugaliae Monumenta Misericordiarum (coord. José Pedro Paiva), 8. ${ }^{\circ}$

9. ${ }^{\circ}$ volumes, Lisboa, União das Misericórdias Portuguesas/ CEHR-UCP, 2010.

J. DIAS PEREIRA, Associativismo Livre. Uma História de Fraternidade e Progresso (18341926), Coimbra, Almedina, 2020. 
M. HALPERN PEREIRA, «As origens do Estado Providência em Portugal: as novas fronteiras entre o público e o privado», in Ler História, n. ${ }^{\circ} 37,1999$, pp. 45-61.

V. ROSENDO, O mutualismo em Portugal: dois séculos de história e suas origens, Lisboa, Montepio Geral/Multinova, 1996.

I. GUIMARÃES SÁ, MA. LOPES, História Breve das Misericórdias Portuguesas, Coimbra, Imprensa da Universidade de Coimbra, 2008.

P. SINGER, Ensaios sobre Economia Solidária, Coimbra, Almedina, 2018. 